\title{
The Effect of a Horticultural Activities Program for the Community Elderly Junko Masuya ${ }^{1^{*}}$, Kikuko Ota ${ }^{2}$ and Yuriko Mashida ${ }^{2}$ \\ ${ }^{1}$ Faculty of Health Sciences, Tokyo Metropolitan University, 7-2-10, Higashiogu, Arakawa-ku, Tokyo 116-8551, Japan \\ ${ }^{2}$ Faculty of Nursing and Medical Care, Keio University, 4411, Endo, Fujisawa-shi, Kanagawa 252-082, Japan
}

\section{Abstract}

Objective: The purpose of this study was to examine the effect of a horticultural activities program for the community elderly.

Methods: The community elderly were invited to participate in a 6-week horticultural activities program. The Intervention groups contained seven participants (3 women and 4 men ; mean age, 69 years). In the participants, demographic data, including age, gender, and experience of horticultural activity were collected, in addition to information relevant to the Geriatric Depression Scale (GDS-15), the Activities of Daily Living (ADL-20) scale, quality of life (QOL), and the Mini-Mental State Examination (MMSE), before and after the intervention.

Results: Regarding QOL, the participants exhibited a significant improvement in "satisfaction with life" after the intervention $(\mathrm{P}<0.05)$. Regarding GDS-15 score, the participants exhibited a significant decrease after the intervention $(P<0.05)$. ADL-20, and MMSE scores remained unchanged after the intervention in both groups.

Conclusions: Participation in horticultural activities reduced depression and increased life satisfaction in elderly residents of the community elderly. However, the number of participants in this study was small, and it was not a randomized controlled trial. Further studies are warranted to completely elucidate the effects of horticultural activities on the psychologic, physical, and cognitive function and QOL of elderly people.

\section{Introduction}

Japan is one of the most rapidly aging countries in the world. The proportion of elderly individuals aged 65 years in Japan is currently about $26.7 \%$, and is expected to rise to $30.0 \%$ by 2030 and $39.9 \%$ by 2060 , when 1 of every 2.5 people will be elderly [1]. It is considered important that elderly people are able to lead lives that are as normal as possible. Therefore, the prevention of dementia has become more important [2]. Many elderly people suffer from depression related to grief or loneliness. Thus, in health-care settings such as nursing homes and day care centers, "nonpharmacologic" approaches are being introduced to help maintain the mental condition of elderly people with dementia [3]. Nonpharmacologic therapies include music, reminiscence, art, and reality orientation therapies, and have been shown to improve quality of life (QOL) and prevent disability among elderly people. Among these therapies, horticultural activities encourage interaction between people and plants [4]. Recently, several studies have described the benefits of horticultural activities for elderly people with dementia, which include improvements in psychologic [5], physical [6], social [7], and cognitive [8] function. Based on these studies, participation in horticultural activities appears to represent a promising method for preventing dementia. However, there is no research that examines the effect of horticultural activities for the community elderly.

\section{Methods}

\section{Participants}

The participants $(\mathrm{n}=7)$ were elderly residents of the community. The distribution of participants is shown in Table 1. The inclusion criteria were as follows:

- $\quad \geq 65$ years of age or older;

- no diagnosis of dementia by a physician;

- no speech or vision disorders; and no participation in other research studies.

\section{Publication History:}

Received: December 21, 2017

Accepted: December 27, 2017

Published: December 29, 2017

\section{Keywords:}

Elderly people, Horticultural activities, Controlled trial, Community

\begin{tabular}{|l|l|l|}
\hline \multirow{2}{*}{ Department } & Response category & $\mathrm{n}(\%)$ \\
\hline \multirow{3}{*}{ Gender } & male & $4(57 \%)$ \\
\cline { 2 - 3 } & FeMale & $3(43 \%)$ \\
\hline \multirow{2}{*}{ Gardening experience } & $60-69$ & $2(29.0 \%)$ \\
\cline { 2 - 3 } & $70-79$ & $4(57.0 \%)$ \\
\cline { 2 - 3 } & $80-$ & $1(14.0 \%)$ \\
\cline { 2 - 3 } & experience & $5(71.0 \%)$ \\
\cline { 2 - 3 } & A lot of experience & $2(29.0 \%)$ \\
\hline
\end{tabular}

Table 1: Distribution of Participants.

The researchers explained the study's objectives and methods and that the potential participants had the freedom of choice to participate in the study. After interviewing each participant, seven provided informed consent to participate.

Demographic data, including information on favorite plants and any experience with plants and plant care, were obtained in advance from each participant.

\section{Intervention methods}

The specialist had several years' experience of caring for elderly people as a nurse, was trained in horticultural techniques, The research

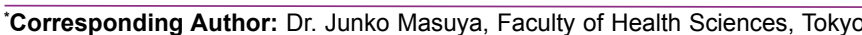
Metropolitan University, 7-2-10, Higashiogu, Arakawa-ku, Tokyo 116-8551, Japan; E-mail: masuya@tmu.ac.jp

Citation: Masuya J, Ota K, Mashida Y (2017) The Effect of a Horticultural Activities Program for the Community Elderly. Int J Nurs Clin Pract 4: 265. doi: https://doi.org/10.15344/2394-4978/2017/266

Copyright: () 2017 Yamamoto et al. This is an open-access article distributed under the terms of the Creative Commons Attribution License, which permits unrestricted use, distribution, and reproduction in any medium, provided the original author and source are credited. 
collaborator evaluated the behavior of each participant. The basic session flow and schedule are shown in Table 2. It was necessary that the seed or plant material used had the following properties: "easy to germinate," "easy to grow," "suitable for the season," "caused sensory stimulation" (seeds and plants of various sizes, form, color, and smell), and "well-known."

\section{Discussion}

Our results demonstrate the benefits of participation in a horticultural activities program on short-term depression and QOL in elderly people. The GDS-15 score and QOL score significantly improved after the intervention. In a 1.5-month, once-weekly

\begin{tabular}{|c|c|c|}
\hline Time & \multicolumn{2}{|l|}{ Content } \\
\hline $1-2 \min$ & \multicolumn{2}{|c|}{ Welcome participants to the activities } \\
\hline $5 \mathrm{~min}$ & \multicolumn{2}{|c|}{ Introductions } \\
\hline $5 \mathrm{~min}$ & \multicolumn{2}{|c|}{ Taking care of plant and observation, sensory stimulation } \\
\hline $15-20 \min$ & \multicolumn{2}{|c|}{$\begin{array}{l}\text { Grow vegetables from seed that germinate easily and are easy to grow } \\
\text { Transplant flowers into individual pots, pruning and harvesting of plants } \\
\text { Pruning and harvesting of plants }\end{array}$} \\
\hline $5 \mathrm{~min}$ & \multicolumn{2}{|c|}{ Sharing the workmanship of plants } \\
\hline $1-2 \min$ & \multicolumn{2}{|l|}{ Closing ceremony } \\
\hline \multirow[t]{2}{*}{ Session } & \multicolumn{2}{|c|}{ Schedule } \\
\hline & Work to arouse memories & New work \\
\hline Week1 & & seeding of baby leaf \\
\hline Week2 & Thinning of baby leaf & Transplant succulent plant \\
\hline Week3 & Fertilizer to the baby leaf & Transplant season flower \\
\hline Week4 & Thinning of baby leaf & Seeding white radish sprouts \\
\hline Week5 & \multicolumn{2}{|c|}{ Harvesting and tasting of red radish sprouts } \\
\hline Week6 & \multicolumn{2}{|c|}{ Harvesting and tasting of baby leaf } \\
\hline
\end{tabular}

\section{Evaluation methods}

Depressive symptoms, activities of daily living (ADL), QOL, and cognitive function of the participants were evaluated. Depressive symptoms were measured using a set of 15 items termed the Geriatric Depression Scale (GDS-15) [9]; ADL was rated using a set of 20 items termed the ADL-20 [10]; QOL was assessed via a set of seven items in the $100-\mathrm{mm}$ visual analogue scale [11]; and cognitive function was evaluated using the MMSE [12]. GDS-15, ADL-20, QOL scores were evaluated by the each participant, and MMSE scores were evaluated by the researcher.

\section{Statistical analyses}

We tested the statistical significance of all alignment results using the Wilcoxon signed-rank test. A SPSS 24.0 statistical software was used for data analysis. A probability ( $p$ ) value of $<0.05$ was considered statistically significant.

\section{Results}

The participation rate for the horticultural activities program was $100 \%$ because no patient dropped out during the study period. The GDS-15, ADL-20, QOL, and MMSE scores are shown in Table 3. ADL-20, and MMSE scores did not significantly change after the intervention compared with those at baseline.

The GDS-15 scores showed significant improvements immediately after the intervention (median, 0.0; range, $0-2$ ) compared with those at baseline (median, 2.0; range, 1-7; $\mathrm{p}<0.05$ ). There were significant improvements in the QOL scores immediately after the intervention (median, 640; range, 370-640) compared with those before participation (median, 600; range, 360-680; $\mathrm{p}<0.05$ ).

\begin{tabular}{|l|l|l|l|}
\hline Evaluation & $\begin{array}{l}\text { Before } \\
\text { median (range) }\end{array}$ & $\begin{array}{l}\text { After 6 weeks } \\
\text { median (range) }\end{array}$ & P-value \\
\hline MMSE & $29(27-30)$ & $30(27-30)$ & 0.32 \\
\hline GDS-15 & $2(1-7)$ & $0(0-2)$ & 0.02 \\
\hline ADL-20 & $12(12-13)$ & $12(11-13)$ & 0.10 \\
\hline QOL & $600(360-680)$ & $640(370-690)$ & 0.03 \\
\hline
\end{tabular}

Table 3: Change in Geriatric Depression Scale-15, Activities of Daily Living-20, quality of life, and Mini-Mental State Examination scores.

GDS-15, Geriatric Depression Scale-15; ADL-20, Activities of Daily Living-20; QOL, quality of life; MMSE, Mini-Mental State Examination.

${ }^{\star} \mathrm{P}<0.05$, Wilcoxon signed-rank test.

intervention (totaling 6 sessions), Sugihara et al. $[13,14]$ reported an improvement in the GDS-15 score. In this study, a total of six sessions of the horticultural activities program were administered over a 1.5 -month period. The term of this study was shorter than those previously described; therefore, our results, which indicate the efficacy of a short-term horticultural activities program on depression, are a new finding.

The significant improvement in the GDS-15 score evident in this study may be attributable to the fact that participants were able to take care of plants and share their experiences, such as deriving satisfaction in their growth and pleasure in harvesting their produce, with others. The physical activity of elderly people and their communication with others tend to decrease when living in a facility, resulting in decreased psychologic function. In this context, the improvement in GDS-15 score obtained in this study is of great significance.

In this study, QOL scores significantly improved after the intervention. To the best of our knowledge, no previous study has reported a significant improvement QOL score after horticultural 
activities in the community elderly people. The results of this study, which demonstrated the efficacy of a short-term horticultural activities program on QOL, constitute a new observation. The horticultural activities continuously provided a sense of responsibility in the daily care of plants. Additionally, the participants were able to eat and share their harvest with others. These factors may underlie the significant improvements observed in QOL score. Considering that with advancing age, people lose interest in their surroundings, the improvements in QOL score obtained in this study are of great significance.

The purpose of this study was to examine the effects of participation in a horticultural activities program on the psychologic, physical, and cognitive function and quality of life of elderly residents of nursing homes. Our results indicate the benefits of the horticultural activities program on short-term depression and "satisfaction with life." The results of this study are consistent with those reported by Sugihara et al. [16], who concluded that a time-limited program of horticultural activities may allow for short-term improvements, but did not promote long-term improvements. Thus, to maintain this effect, it may be necessary to provide a sustained intervention.

The major limitations of this study were the small number of participants and the nonrandomized nature of the trial. Therefore, further, randomized controlled trials involving a greater number of participants are necessary to confirm the effects of a long-term horticultural activities program for elderly people.

\section{Conclusion}

The purpose of this study was to examine the effects of participation in a horticultural activities program on psychologic, physical, and cognitive function and quality of life of community elderly people. These results indicate the ability of horticultural activities to improve short-term depression and QOL, and suggest that this program may be an effective treatment modality to improve depression and QOL with life in the elderly population.

\section{Competing Interests}

The author declears that they have no competing interest exists.

\section{References}

1. The estimation of population in Japan, National Institute of Population and Social Security Research.

2. Urakami K (2007) Prevention of dementia. Psychogeriatrics 7: 93-97.

3. Jinbo D, Kimura $Y$, Taniguchi M, et al. Effect of aromatherapy on patients with Alzheimer's disease. Psychogeriatrics 2009; 9: 173-179.

4. Masuya J, Ota K (2014) Efficacy of horticultural activity in elderly people with dementia: A pilot study of the influence on vitality and cognitive function. International Journal of Nursing \& Clinical Practices 1: 101.

5. Sugihara S, Aoyama H, Sugimoto M, et al. (2006) The psychological cognitive and immunological effects of hortcultural therapy on the elderly living in a nursing home. Japanese Journal of Geriatric Psychiatry 17: 967975

6. Brown VM, Allen AC, Dwozan M, Mercer I, Warren K (2004) Indoor gardening and older adults-effect of socialization, activities of daily living and loneliness. J Gerontol Nurs 30: 34-42.

7. Tse MM (2009) Therapeutic effects of an indoor gardening programme for older people living in nursing homes. J Clin Nurs 19: 949-958.

8. Yamada S, Toba K (2005) A prospective comparison of day care and freely chosen occupational therapy for elderly patients with dementia. Nihon Ronen Igakkai Zasshi 42: 83-89.
9. Sheikh JI, Yesavage JA (1986) Geriatric Depression Scale (GDS): Recent evidence and development of a shorter version. Clinical Gerontologist 5 : 165-173.

10. Eto F, Tanaka M, Chishima M, Igarashi M, Mizoguchi T, et al. (1992) Comprehensive activities of daily living (ADL) index for the elderly. Japan Journal of Geriatrics 29: 841-848.

11. Matsubayashi K, Okumiya K, Osaki Y, Fujisawa M, Doi Y (1997) Quality of life of old people living in the community. Lancet 350: 1521-1522.

12. Folstein MF, Folstein SE, Mchugh PR (1975) "Mini Mental State". A practical method for grading the cognitive state of patients for the clinicians. J Psychiatr Res 12: 189-198.

13. Sugihara S, Aoyama H, Sugtmoto M, et al. (2006) The psychological, cognitive and immunological effects of horticultural therapy on the elderly living in a nursing home. Japanese Journal of Geriatric Psychiatry; 17: 967975.

14. Sugihara S, Aoyama H, Takeda S, et al. (2005) The psychological and behavioral effect of horticultural therapy on the elderly living in a nursing home. Japanese Journal of Geriatric Psychiatry 16: 1163-1173. 